\title{
The knowns and unknowns in research
}

\author{
ANDY DONG \\ Design Computing and Cognition, University of Sydney, Sydney, Australia
}

Referencing a now (in)famous quote by Donald Rumsfeld about "unknown unknowns," there are also problems in research that are known unknowns and unknown unknowns. The problems are characterized by the degree to which we know what it is that we are solving and how to solve it.

There are those problems we know about and know how to solve; all we have to do is find a competent person to do the work. These problems are generally uninteresting to the research community, and they are the kinds of problems doctoral students typically solve in their preliminary examinations.

There are problems we know about but do not know how to solve entirely. We try a solution method, we publish our best results, and the field advances through improvements that build upon the state of the art. Generative systems (Emdanat, Stiny, \& Vakaló, 1999) and configuration (Soininen \& Stumptner, 2003) are classic examples of this type of problem.

Then there are the unknown problems with a known solution methodology. These are the problems that we did not know about, perhaps because we encountered them on the way to solving a more general problem, but we know how to solve them because they share structural similarities to problems we have solved in the past. These types of research problems are also published in AI EDAM, generally as practicum papers, which present a solution to a novel, unique, and surprising problem, although the solution principle is itself generally well known.

This brings us to the last type of problem, the unknown unknowns. This is the kind of problem that we do not know about, or perhaps more accurately, problems that we do not fully understand or that hide underlying problems we will not even know about until we attempt a solution, and we do not really know how to solve them. Complex systems are a canonical example of this type of problem, wherein the very definition of complexity is itself often contingent on the specific problem domain and eludes strict codification. For example, consider the problem of quantifying the complexity of product architecture, for which a hierarchic structure is taken as a defining characteristic (Hofer \& Halman,

Reprint requests to: Andy Dong, Design Computing and Cognition, Wilkinson Building (G04), University of Sydney, Sydney, NSW 2006, Australia. E-mail: andy.dong@sydney.edu.au
2004). Hierarchy is dependent upon on the degree of coupling of components, which is known as modularity (Hölttä-Otto \& de Weck, 2007), but finding modularity is itself an open problem (Sarkar \& Dong, 2011).

Perhaps the most important complex system that we know surprisingly little about is the human mind and the faculty of design. One of the original "grand challenges" for the field of artificial intelligence in design was to produce an intelligent design machine (Gray, 1988), and various computational models of design and associated "machines that design" have been provided over the years. Despite improving our understanding of the problem of intelligent design machines, as I stated in an article in this Journal (Dong, 2010), we know alarmingly little about the most important intelligent design machine, humans, and how humans became a species that can design the world to suit their survival with a degree of flexibility that is unmatched by any other species. Our community is notably absent from debates on the emergence of mental capacities for tool making in the archaeological record and we have no equivalent debate to that surrounding linguistic competence, or what I have described as design competence (Dong, 2010). Computational research in the evolution of syntax using artificial life means (Kirby, 2002) has demonstrated the value of computation in explaining the emergence of language. Combining computation with theories of design to explain the evolution toward human faculty of design would be a worthy challenge for this community and this Journal, and one that we should undertake even if we do not know what the research questions are exactly or what the methodological approaches should be. This is probably an unknown unknown that could delightfully befuddle us for decades to come.

\section{REFERENCES}

Dong, A. (2010). Biological first principles for design competence. Artificial Intelligence for Engineering Design, Analysis and Manufacturing 24(4), 455-466.

Emdanat, S., Stiny, G., \& Vakaló, E.-G. (1999). Generative systems in design. Artificial Intelligence for Engineering Design, Analysis and Manufacturing 13(4), 239-240.

Gray, M.A. (1988). An intelligent design machine: architecture and search strategies. Artificial Intelligence for Engineering Design, Analysis and Manufacturing 2(2), 105-122.

Hofer, A.P., \& Halman, J.I.M. (2004). Complex products and systems: potential from using layout platforms. Artificial Intelligence for Engineering Design, Analysis and Manufacturing 18(1), 55-69. 
Hölttä-Otto, K., \& de Weck, O. (2007). Degree of modularity in engineering systems and products with technical and business constraints. Concurrent Engineering 15(2), 113-126.

Kirby, S. (2002). Natural language from artificial life. Artificial Life 8(2), $185-215$.
Sarkar, S., \& Dong, A. (2011). Community detection in graphs using singular value decomposition. Physical Review E 83(4).

Soininen, T., \& Stumptner, M. (2003). Special issue: configuration [Editorial]. Artificial Intelligence for Engineering Design, Analysis and Мапиfacturing 17(1), 1-2. 